\section{Developments in Chemicals' Control* Emerge at OECD High-level Meeting}

New developments in international efforts to protect Man and his environment from unintended effects of chemicals emerged recently at the Second OECD Highlevel Meeting on Chemicals**. Ministers and senior officials from OECD Member countries agreed on a number of measures to improve the effective management of chemicals and to streamline international cooperation in this field. The emphasis was particularly on steps to advance international harmonization of chemical control policies, and to ensure implementation of recommendations on the testing and assessment of chemicals stemming from the OECD's First High-level Meeting on Chemicals in 1980, which agreed on initial steps aimed at the protection of Man and the environment from chemicals. The Second such Meeting agreed on steps to harmonize further the approaches to the assessment of potential chemical hazards, and to enhance the international sharing between governments of information on chemicals.

The High-level Meeting endorsed a set of principles to guide the exchange of confidential data on chemicals between governments, while providing appropriate safeguards to protect their commercial value. The Meeting also endorsed categories of data on chemicals which can be exchanged freely. This is [believed to be] the first time that such a list of non-confidential data has been recognized at the international level.

The Meeting gave the 'green light' to proceed with a set of guidelines which will assist in the interpretation of chemicals' data. By providing a common basis for performing hazard assessments, use of the guidelines will help to ensure more consistent protection of Man and the environment, and reduce costs associated with the retesting and reassessment of chemicals that are traded internationally.

The Meeting also agreed upon a common approach in Member countries to assure the quality of test data, and upon procedures for the mutual recognition of such national approaches. This represents a major step towards implementation of the landmark decision of the OECD Council in 1981 to ensure mutual acceptance of data between Member countries.

The importance of these measures, both for the safety of the environment and the maintenance of a vigorous chemical industry, can be better understood against some background data on the industry itself. There are currently from fifty to seventy thousand $(50,000-70,000)$ chemicals produced in commercial quantities, with roughly an additional one thousand $(1,000)$ new chemicals entering the market every year. Chemicals' sales in the OECD sector top US $\$ 300$ thousand millions annually and account for $2-3 \%$ of Gross Domestic Product in the Organization's membership. The OECD countries produce more than two-thirds of the world's chemicals, and account for about four-fifths of international chemicals' trade.

Each Government has to take account of a number of interrelated social and economic concerns in trying to achieve efficient and cost-effective strategies to protect and manage the environment. In the case of chemicals, the challenge is [particularly great] because of the potential economic and trade impacts that could arise if nations were to adopt widely-differing control régimes.

International cooperation in OECD is helping governments 'to meet this challenge. The results of this and earlier meetings will help to harmonize national régimes for the control of chemicals, improve protection of Man and the environment, prevent impediments to trade, as well as reduce the need for duplicative testing and the heavy costs that go with it. Our work here helps us all to make the difficult decisions at home.

The spirit of cooperation which had characterized the Meeting was particularly gratifying, as was the outcome of discussions on the proposed Minimum Pre-marketing set of Data now pending before the Organization's Council. In the proposed Council action, Member countries would agree that sufficient information on properties of new chemicals should be available before they are marketed, to ensure that a meaningful assessment of hazards to Man and the environment can be carried out. Through its discussions, the Second High-level Meeting laid the ground for Council action on this important element in our continuing efforts to harmonize our approaches to the control of chemicals.

Through the enactment or implementation of chemicals' control laws, countries will be greatly assisted by the OECD work on an International Glossary of Key Terms. (A final report of the OECD Expert Group on this was endorsed by the Meeting.)

As for discussions at the Meeting on Major Challenges for the Eighties, we are entering the next phase in the OECD Chemicals Programme, with some new issues to consider. The Meeting agreed to continue and strengthen efforts by the OECD in the promotion of international cooperation in the management of chemicals, and identified as an area of particular concern the need for improved cooperation in the assessment of chemicals that are currently on the world market. This work is particularly relevant in the light of the very many chemicals that are currently available, though the presence of 50,000 chemicals does not mean we have 50,000 problems!**

The tangible results of the OECD Chemicals Programme to date, and the affirmation of its commitment to further cooperation, auger well for the future, [especially with] the leadership of many countries in accomplishing work in the OECD Chemicals Programme-including work on step-sequence testing, hazard assessment, and information exchange associated with the export of chemicals.

J. BlaIR SEABORN, Deputy Minister
Environment Canada
Fontaine Building ( Hull)
Ottawa
Ontario KIA OH3
Canada.

* Substance of Chairman's concluding statement on 17 November 1982 to the OECD (Organization for Economic Cooperation and Development) Second High-level Meeting on Chemicals, c/o OECD, 2 rue André-Pascal, 75775 Paris, France.-Ed.

** Here we are vividly reminded of the United Nations Environment Programme's International Register of Potentially Toxic Chemicals, described by Drs Alexander I. Kucherenko \& Jan W. Huismans in Environmental Conservation, Vol. 9, No. 1, pp. 59-63, 1982, and of the review, by Dr Gordon C. Butler, on page 81 of the present issue, of their latest major publication. -Ed. 